\title{
Viscosities of Binary Liquid Mixtures of 1, 2-Dichloroethane with Pyridine, Dimethyl Sulfoxide, Acetone, Furan and Tetrahydrofuran at $303.15 \mathrm{~K}$
}

\author{
Atri Deo Tripathi*, Asim Ahmad \\ Dept. of Chemistry, College of Engineering, Teerthanker Mahaveer University, Moradabad, India \\ Email address: \\ atri34tmu@gmail.com (A. D. Tripathi), drasim.engineering@tmu.ac.in (A. Ahmad) \\ ${ }^{*}$ Corresponding author
}

\section{To cite this article:}

Atri Deo Tripathi, Asim Ahmad. Viscosities of Binary Liquid Mixtures of 1, 2-Dichloroethane with Pyridine, Dimethyl Sulfoxide, Acetone, Furan and Tetrahydrofuran at 303.15 K. American Journal of Engineering and Technology Management. Vol. 2, No. 6, 2017 , pp. 87-92. doi: 10.11648/j.ajetm.20170206.13

Received: March 10, 2017; Accepted: April 5, 2017; Published: November 29, 2017

\begin{abstract}
Kinematic Viscosities, $v$, at $\mathrm{T}=303.15 \mathrm{~K}$, have been measured for binary liquid mixtures of 1, 2-dichloroethane with pyridine, dimethyl sulfoxide (DMSO), acetone, furan and tetrahydrofuran (THF). The values of $v$ have been fitted in appropriate equations using a least squares method. The values of the quantity $\Delta v$, which refer to the deviations of the experimental values of the dynamic viscosities of the mixtures from the mole fraction mixture law values, have been calculated. Further analysis has indicated that McAllister's approach correlates $v$ of the investigated mixtures all over the entire composition range to a appreciably high degree of accuracy.
\end{abstract}

Keywords: Viscosity, 1, 2-Dichloroethane, Acetone, Binary Mixtures, Specific Interaction

\section{Introduction}

Binary systems of 1,2 dichloroethane $\left(\mathrm{CH}_{2} \mathrm{ClCH}_{2} \mathrm{Cl}\right)$ with pyridine, dimethyl sulfoxide, acetone, furan and tetrahydrofuran are remarkable from the perspective of the specific interaction between the components of the diverse binary systems in the liquid state. The specific interaction of $\mathrm{CH}_{2} \mathrm{ClCH}_{2} \mathrm{Cl}$ can be visualized to be on account of the occurrence of two $\mathrm{Cl}$ atoms and four $\mathrm{H}$ atoms in $\mathrm{CH}_{2} \mathrm{ClCH}_{2} \mathrm{Cl}$, due to which it can act as $\sigma$ - acceptor towards and be involved in the creation of hydrogen bond with all latter compounds, which will act as n-donors.

Solvents with a dielectric constant greater than 15 can be divided into protic and aprotic. Protic solvents solvate anions strongly via hydrogen bonding. Water is a protic solvent. Aprotic solvents such as acetone or dichloromethane have a tendency to have large dipole moments (separation of partial positive and partial negative charges within the same molecule) and solvate positively charged species via their negative dipole. In chemical reactions the use of polar protic solvents favors the $\mathrm{S}_{\mathrm{N}} 1$ reaction mechanism, while polar aprotic solvents favor the $\mathrm{S}_{\mathrm{N}} 2$ reaction mechanism.
Wide-ranging studies concerning interactions between components of Chloroalkanes with ketones of more complexity have not been made in the literature. However, Tripathi have made the measurements of excess enthalpies[1-3] for such binary liquid mixtures. These measurements have been discussed in the light of the of electron donor -acceptor interaction. Since, the viscosities for binary liquid mixtures are known [4-6] to provide information on the existence of a interaction between the components, therefore in order to get information about the interaction of $\mathrm{CH}_{2} \mathrm{CICH}_{2} \mathrm{CI}$ with pyridine, dimethyl sulfoxide, acetone, furan and tetrahydrofuran, we have made measurements on viscosity for above-mentioned systems.

In addition, there is a also current interest to examine to what accuracy the approaches of McAllister [7] and Lobe [8] can calculate the viscosities of binary liquid mixtures of components of different composition. Hence, in this program, the measurements of kinematic viscosities of binary liquid mixtures of $\mathrm{CH}_{2} \mathrm{CICH}_{2} \mathrm{CI}$ with pyridine, dimethyl -sulfoxide, acetone, furan and tetrahydrofuran have been made at $303.15 \mathrm{~K}$, and the results obtained have been reported and interpreted in this paper. 


\section{Experimental Section}

\subsection{Materials}

The methods of purification of the different liquids and checking their purity has been given elsewhere [1-3].

\subsection{Method}

The kinematic viscosities of the different pure liquids and their binary mixtures considered in the present program were measured at $303.15 \pm 0.01$ with the help of kinematic viscometer of Tuan and Fuoss [9], as given elsewhere[10]. The temperature of the water thermostat in which the viscometer was placed during the experiment was read with a two-junction copper-constantan thermopile, by means of a precision vernier potentiometer (Scientific Pye Instrument, England), and the flow times of the different pure liquids and their binary mixtures were noted with a stop watch which could read correct to $\pm 0.1 \mathrm{~s}$. The accuracy in the kinematic viscosities $v$ reported in the present measurement is of the order of $\pm 0.001 \mathrm{cSt}$.

\section{Experimental Procedure}

The viscometer was properly mounted vertically on a wooden stand which was specially constructed for this purpose. It was then thoroughly cleaned and dried. Known amount of the liquid was introduced in the lower reservoir through the mouth of the side tube, by means of hypodermic syringe having straight needle. After closing the mouth of the side tube with the cover, the whole assembly was kept in a thermostat maintained at $303.15 \mathrm{~K}$. After sometime (about two hrs.), when the contents of the viscometer was maintained at the required temperature, the viscometer was tilted quickly to run liquid through the side tube from the lower reservoir to top reservoir. The viscometer (mounted on wooden stand) was again held in the vertical position in the thermostat. Bulb was filled by liquid component and the time taken by liquid to flow from the two reference marks in the capillary was noted by means of a stop watch which could read correct to $\pm 0.1 \mathrm{~s}$. The viscometer was first calibrated by noting the flow times for acetone and cyclohexane at $303.15 \mathrm{~K}$, and then calculating the constants $\mathrm{A}^{\prime}$ and $\mathrm{B}^{\prime}$ of the equation

$$
\eta / \rho=A^{\prime} t-\frac{B^{\prime}}{t}
$$

where $\eta / \rho$ is kinematic viscosity, $\eta$ refers to the dynamic viscosity and $\rho$ is the density. By using the dynamic viscosity in centipoise, $\rho$ in in $\mathrm{g} \mathrm{cm}^{-3}$ and time $\mathrm{t}$ in seconds, the values of the constants A' and B'may be evaluated for the kinematic viscometer used in the present programme. The measurements of kinematic viscosities were first made for pure liquids and their binary mixtures studied in the present programme. Kinematic viscosities will be converted to dynamic viscosities $\eta$ by use of densities which, for pure liquids and their mixtures were measured by using a vibrating tube densimeter (model DMA,Anton -Paar 60/602) [7] at 303.15K.

\section{Results}

The values of the kinematic viscosities, $v$, for the different pure liquids and binary mixtures of $\mathrm{CH}_{2} \mathrm{ClCH}_{2} \mathrm{Cl}$ with pyridine, dimethyl sulfoxide, acetone, furan and tetrahydrofuran at $303.15 \mathrm{~K}$ are given in Table 1 , where $x$ refers to the mole fraction of $\mathrm{CH}_{2} \mathrm{ClCH}_{2} \mathrm{Cl}$. The experimental values of $v$ for pyridine, dimethyl sulfoxide, acetone, furan and tetrahydrofuran, and $\mathrm{CH}_{2} \mathrm{ClCH}_{2} \mathrm{Cl}$ at $303.15 \mathrm{~K}$ have been found to be $1.238,0.82,0.379,0.338,0.49$ and $0.590 \mathrm{cSt}$, respectively, which are in excellent agreement with the corresponding literature values [8] (obtained from the dynamic viscosities by making use of the density data) $1.238,0.82$, $0.379,0.338,0.49$ and $0.590 \mathrm{cSt}$, respectively, for the different liquids in the same order. The values of $v$ for the different mixtures of $\mathrm{CH}_{2} \mathrm{ClCH}_{2} \mathrm{Cl}$ at $\mathrm{T}=303.15 \mathrm{~K}$ have been plotted against $x$ in Figure 1. The values of $v$ for the mixtures have been fitted by the method of least squares to the equation

$$
v=x(1-x)\left[B_{0}+B_{1}(2 x-1)+B_{2}(2 x-1)^{2}+B_{3}(2 x-1)^{3}\right.
$$

Table 1. Values of the Experimental and Estimated Kinematic Viscosities for

\begin{tabular}{|c|c|c|c|c|c|}
\hline \multicolumn{2}{|l|}{$x$} & vexptl/cSt & vcaltd/cSt & & $\Delta v$ \\
\hline $\begin{array}{l}\text { 1,2-Dich } \\
\text { pyridine }\end{array}$ & hane- & & eq3 & eq5 & \\
\hline 0.000 & & 1.238 & & & \\
\hline 0.1165 & & 1.224 & 1.230 & 1.235 & 0.06 \\
\hline 0.2587 & & 1.206 & 1.211 & 1.212 & 0.14 \\
\hline 0.3498 & & 1.187 & 1.195 & 1.190 & 0.17 \\
\hline 0.4183 & & 1.105 & 1.113 & 1.115 & 0.17 \\
\hline 0.5343 & & 1.043 & 1.051 & 1.046 & 0.15 \\
\hline 0.6787 & & 0.989 & 0.998 & 0.997 & 0.19 \\
\hline 0.7685 & & 0.945 & 0.953 & 0.965 & 0.20 \\
\hline 0.8567 & & 0.865 & 0.872 & 0.875 & 0.18 \\
\hline 0.9233 & & 0.672 & 0.675 & 0.678 & 0.03 \\
\hline 1.0000 & & 0.592 & & & \\
\hline \multicolumn{6}{|c|}{ 1,2-Dichloroethane-dimethylsulfoxide } \\
\hline 0.000 & 0.82 & & & & \\
\hline 0.1333 & 0.801 & 0.802 & 0.827 & & \\
\hline 0.3112 & 0.778 & 0.779 & 0.796 & & \\
\hline
\end{tabular}
the Various Systems of 1,2-Dichloroethane at $303.15 \mathrm{~K}$.

\begin{tabular}{lllll}
\hline \multicolumn{5}{l}{ 1,2-Dichloroethane-dimethylsulfoxide } \\
\hline 0.4222 & 0.774 & 0.775 & 0.781 & 0.05 \\
0.5234 & 0.734 & 0.735 & 0.739 & 0.03 \\
0.6877 & 0.711 & 0.712 & 0.715 & 0.05 \\
0.7454 & 0.695 & 0.695 & 0.698 & 0.04 \\
0.8554 & 0.646 & 0.647 & 0.648 & 0.02 \\
0.9665 & 0.607 & 0.608 & 0.612 & 0.01 \\
1.0000 & 0.592 & & & \\
\hline \multicolumn{7}{c}{} \\
\hline 1,2-Dichloroethane-furan & & & \\
\hline 0.000 & 0.338 & & & \\
0.1232 & 0.345 & 0.346 & 0.348 & -0.02 \\
0.2462 & 0.378 & 0.379 & 0.383 & -0.02 \\
0.3476 & 0.393 & 0.394 & 0.397 & -0.03 \\
0.4654 & 0.416 & 0.417 & 0.418 & -0.04 \\
0.5465 & 0.456 & 0.457 & 0.460 & -0.02 \\
0.6598 & 0.478 & 0.479 & 0.482 & -0.03 \\
0.7687 & 0.498 & 0.499 & 0.506 & -0.04 \\
0.8234 & 0.535 & 0.536 & 0.539 & -0.01 \\
0.9334 & 0.567 & 0.568 & 0.572 & -0.01 \\
1.0000 & 0.592 & & & \\
\hline
\end{tabular}




\begin{tabular}{lllll}
\hline \multicolumn{5}{l}{ 1,2-Dichloroethane-tetrahydrofuran } \\
\hline 0.000 & 0.49 & & & \\
0.1754 & 0.508 & 0.502 & 0.505 & 0.00 \\
0.2567 & 0.518 & 0.519 & 0.522 & 0.00 \\
0.3456 & 0.531 & 0.532 & 0.535 & 0.01 \\
0.4536 & 0.549 & 0.550 & 0.555 & 0.01 \\
0.5437 & 0.556 & 0.557 & 0.559 & 0.01 \\
0.6453 & 0.565 & 0.566 & 0.569 & 0.01 \\
0.7542 & 0.571 & 0.572 & 0.578 & 0.00 \\
0.8543 & 0.581 & 0.582 & 0.585 & 0.00 \\
0.9145 & 0.587 & 0.588 & 0.593 & 0.00 \\
1.0000 & 0.592 & & & \\
\hline
\end{tabular}

\begin{tabular}{lllll}
\hline \multicolumn{6}{l}{ 1,2-Dichloroethane-acetone } & & & \\
\hline 0.0000 & 0.379 & & & \\
0.1123 & 0.394 & 0.395 & 0.398 & -0.01 \\
0.2434 & 0.424 & 0.425 & 0.425 & -0.01 \\
0.3346 & 0.443 & 0.454 & 0.457 & -0.01 \\
0.4564 & 0.467 & 0.468 & 0.472 & -0.01 \\
0.5123 & 0.481 & 0.482 & 0.484 & -0.01 \\
0.6223 & 0.494 & 0.495 & 0.497 & -0.02 \\
0.7767 & 0.511 & 0.512 & 0.515 & -0.03 \\
0.8443 & 0.529 & 0.530 & 0.535 & -0.03 \\
0.9416 & 0.546 & 0.547 & 0.549 & -0.03 \\
1.000 & 0.592 & & & \\
\hline
\end{tabular}

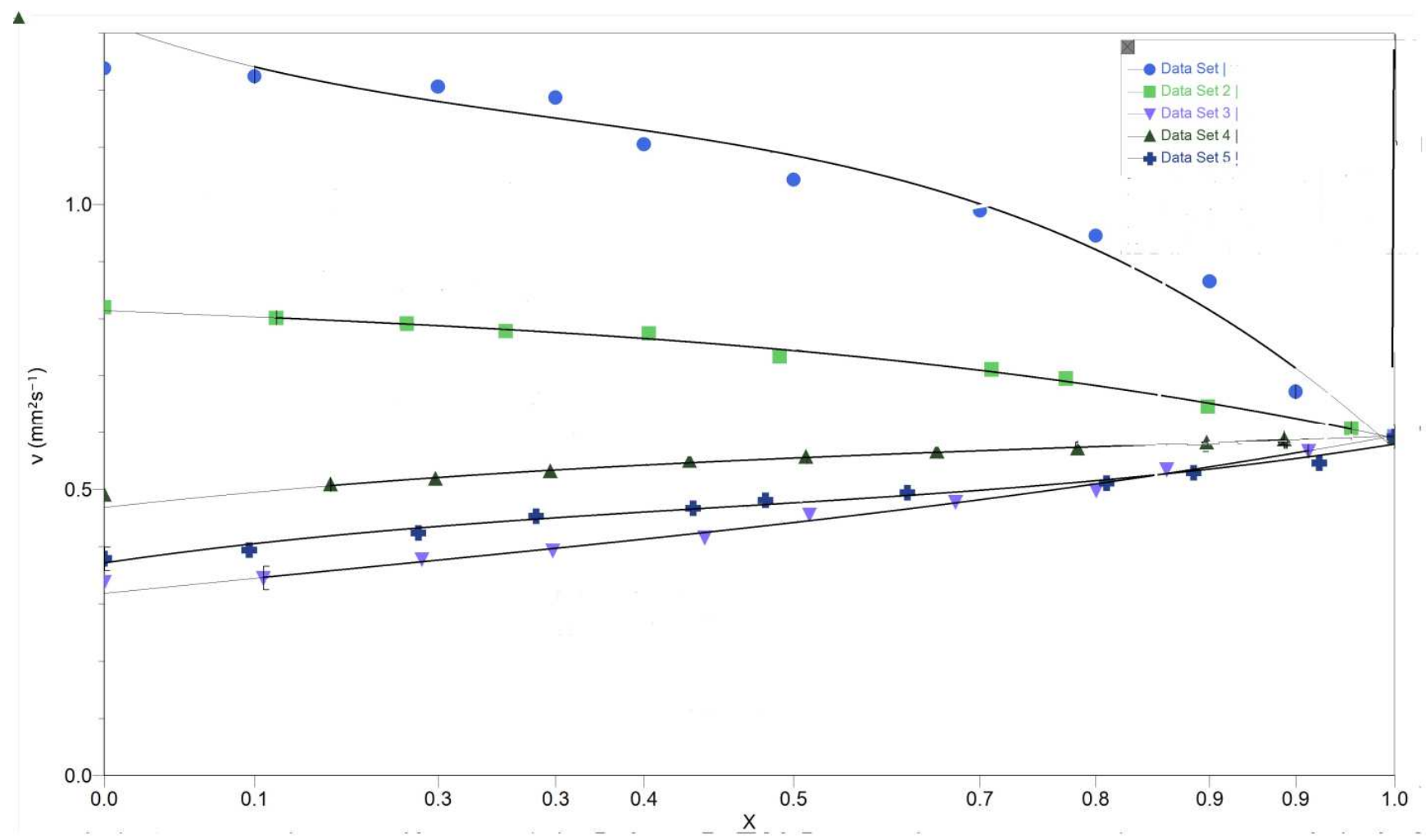

Figure 1. Plot of $v$ Vs mole fraction $x$ for various mixtures at $303.15 \mathrm{~K}$.

$x_{\mathrm{xCH} 2 \mathrm{ClCH} 2 \mathrm{Cl}+(1-\mathrm{x}) \text { Pyridine, }} \mathrm{xCH} 2 \mathrm{ClCH} 2 \mathrm{Cl}+(1-\mathrm{x})$ dimethyl sulfoxide

$\nabla \mathrm{xCH} 2 \mathrm{ClCH} 2 \mathrm{Cl}+(1-\mathrm{x})$ furan, $\boldsymbol{\wedge} \mathrm{xCH} 2 \mathrm{ClCH} 2 \mathrm{Cl}+(1-\mathrm{x})$ tetrahydrofuran

$\mathrm{xCH} 2 \mathrm{ClCH} 2 \mathrm{Cl}+(1-\mathrm{x})$ acetone.

where $x$ refers to mole fraction of $\mathrm{CH}_{2} \mathrm{Cl} . \mathrm{CH}_{2} \mathrm{Cl}$ and has uncertainty of \pm 0.0001 . The values of parameters $B_{0}, B_{1}, B_{2}$, and $B_{3}$ of eq 2 , along with the standard deviations, are collected in Table 3 .

Table 2. Different values of the parameters $v_{A B}$ and $v_{B A}$ from eq 3, Standard Deviations, $\delta(v)$, and Aerage percent Deviations,,( $\left.4 \%\right)$ av, and the maximum percent deviations, (4\%)max for the various systems of 1,2-Dichloroethane at $303.15 \mathrm{~K}$.

\begin{tabular}{|c|c|c|c|c|c|c|c|}
\hline System & $\mathbf{V}_{\mathrm{AB}}$ & $\mathbf{V}_{\mathbf{B A}}$ & $\delta(v), *$ & $(\Delta \%)$ av & & $(\Delta \%$ & \\
\hline & & & & eq3 & eq5 & eq3 & eq5 \\
\hline $\mathrm{CH}_{2} \mathrm{ClCH}_{2} \mathrm{Cl}$-pyridine & 0.099 & 1.01 & 0.0026 & 0.22 & 10.6 & 0.54 & 14.8 \\
\hline $\mathrm{CH}_{2} \mathrm{ClCH}_{2} \mathrm{Cl}-\mathrm{DMSO}$ & 0.734 & 0.755 & 0.0031 & 0.19 & 9.8 & 0.23 & 11.0 \\
\hline $\mathrm{CH}_{2} \mathrm{ClCH}_{2} \mathrm{Cl}$-furan & 0.435 & 0.453 & 0.0027 & 0.06 & 0.69 & 0.14 & 1.5 \\
\hline $\mathrm{CH}_{2} \mathrm{ClCH}_{2} \mathrm{Cl}-\mathrm{THF}^{* *}$ & 0.743 & 0.764 & 0.0018 & 0.56 & 4.4 & 0.86 & 24 \\
\hline $\mathrm{CH}_{2} \mathrm{ClCH}_{2} \mathrm{Cl}$-acetone & 0.465 & 0.486 & 0.0012 & 0.27 & 19.3 & 0.65 & 17.2 \\
\hline
\end{tabular}

*equation $2, * *$ tetrahydrofuran

Units of $\mathrm{v}_{\mathrm{AB}}, \mathrm{v}_{\mathrm{BA}}$ and $\delta(\mathrm{v})$ are cSt. 
Table 3. Values of the parameters of Eq.2 and the standard deviations, $\delta$, for the Various mixtures at $303.15 \mathrm{~K}$.

\begin{tabular}{|c|c|c|c|c|c|}
\hline Property & B0 & B1 & B2 & B3 & $\delta$ \\
\hline $\mathrm{v} / \mathrm{mm}^{2} \cdot \mathrm{s}^{-1}$ & 1.100 & $\begin{array}{l}x \mathrm{CH}_{2} \mathrm{Cl} . \mathrm{CH}_{2} \mathrm{Cl}+(1-x) \text { pyridine } \\
-0.2002 \\
x \mathrm{CH}_{2} \mathrm{Cl} \cdot \mathrm{CH}_{2} \mathrm{Cl}+(1-x) \text { DMSO }\end{array}$ & -0.1555 & -0.1741 & 0.004 \\
\hline $\mathrm{v} / \mathrm{mm}^{2} \cdot \mathrm{s}^{-1}$ & 0.7506 & $\begin{array}{l}-0.09592 \\
x \mathrm{CH}_{2} \mathrm{Cl} . \mathrm{CH}_{2} \mathrm{Cl}+(1-x) \text { furan }\end{array}$ & -0.04870 & -0.01633 & 0.008 \\
\hline $\mathrm{v} / \mathrm{mm}^{2} \cdot \mathrm{s}^{-1}$ & 0.4331 & $\begin{array}{l}0.1264 \\
x \mathrm{CH}_{2} \mathrm{Cl} . \mathrm{CH}_{2} \mathrm{Cl}+(1-x) \mathrm{THF}\end{array}$ & 0.02307 & 0.01143 & 0.009 \\
\hline $\mathrm{v} / \mathrm{mm}^{2} \cdot \mathrm{s}^{-1}$ & 0.5510 & $\begin{array}{l}0.05091 \\
x \mathrm{CH}_{2} \mathrm{Cl} . \mathrm{CH}_{2} \mathrm{Cl}+(1-x) \text { acetone }\end{array}$ & -0.02006 & 0.01169 & 0.002 \\
\hline $\mathrm{v} / \mathrm{mm}^{2} \cdot \mathrm{s}^{-1}$ & 0.4715 & 0.06903 & 0.003611 & 0.03475 & 0.01021 \\
\hline
\end{tabular}

\section{Discussion}

We shall analyze below our kinematic viscosity data for the different liquid mixtures in light of the various theories of liquid mixture viscosity. The various approaches for estimation of viscosities of liquid mixtures have been discussed by Reid, Prausnitz, and Sherwood [13]. One approach for viscosity estimation of liquid-mixture is due to McAllister [8] who has adopted the Eyring approach [13, 14] and has considered the interaction between layers of molecules in the velocity gradient to involve activated jumps of molecules between layers. the molecule has been treated as if the molecule were undergoing a chemical reaction and has to overcome a potential barrier in this process. For a binary mixture of $A$ and $B$ in which case molecular interactions of A-A-A, B-B-B, A-B-A. B-A-B, A-A-B, and A-B-B types can be visualized, McAllister's approach yields the equation (3)

$\ln v=x_{A}^{3} \ln v_{A}+3 x_{A}^{2} x_{B} \ln v_{A B}+3 x_{A} x_{B}^{2} \ln v_{B A}+x_{B}^{3} \ln v_{B}+R^{0}$

where

$$
\mathrm{R} 0=x_{B} 3 \ln \frac{M_{B}}{M_{A}}+3 x_{A} x_{B}^{2} \ln \left\{1+\frac{M_{B}}{M_{A}} / 3\right\}+3 x_{A}^{2} x_{B} \ln \left\{2+\frac{M_{B}}{M_{A}} / 3\right\}-\ln \left(x_{A}+x_{B} \frac{M_{B}}{M_{A}}\right)
$$

Where $v_{\mathrm{A}}$ and $v_{\mathrm{B}}$ represents Kinematic viscosities of the pure components $\mathrm{A}$ and $\mathrm{B}$, respectively, and $v$ is denoted for the kinematic viscosity of the mixture of $\mathrm{A}$ and $\mathrm{B}$ having mole fractions $\mathrm{x}_{\mathrm{A}}$ and $\mathrm{x}_{\mathrm{B}}$ respectively. $v_{\mathrm{AB}}$ and $v_{\mathrm{BA}}$ are the two undetermined parameters which are characteristics of a system of $\mathrm{A}$ and $\mathrm{B}$. Further $\mathrm{M}_{\mathrm{A}}$ and $\mathrm{M}_{\mathrm{B}}$ in eq 4 are molecular weights of a component of $\mathrm{A}$ and $\mathrm{B}$. Here 1, 2, dichloroethane is taken as $\mathrm{A}$ whereas other components as $\mathrm{B}$ in all the systems, we have determined the values of the parameters $v_{\mathrm{AB}}$ and $v_{\mathrm{BA}}$ by the method of least squares from the viscosity data for the various systems. The values of the parameters, $v_{\mathrm{AB}}$ and $v_{\mathrm{BA}}$ along with the standard deviations $\delta(v)$ for the various systems, are summarized in Table 2. The values of kinematic viscosities, $v_{\text {cald }}$ of the various mixtures, as calculated from eq 3 , using the values of the $v_{\mathrm{AB}}$ and $v_{\mathrm{BA}}$, are collected in Table 1 . The average percent deviations, $(\Delta \%)_{\mathrm{av}}$, and the maximum percent deviations, $(\Delta \%)_{\max }$, of the experimental data of $v$ from those estimated for the various mixtures by using eq 2 are collected in Table 2 . It can be seen that McAllister's eq 3 correlates the liquid -mixture viscosity data for the above mentioned mixtures to a high degree of accuracy.

As per Lobe's approach $[8,12]$, the kinematic viscosities $v$ of a binary mixture of $A$ and $B$ is given by

$$
v=\phi_{\mathrm{A}} v_{\mathrm{A}} \mathrm{e}^{\Phi \mathrm{B} \alpha^{*} \mathrm{~B}}+\phi_{\mathrm{B}} v_{\mathrm{B}} \mathrm{e}^{\phi \mathrm{A}^{*}{ }_{\mathrm{A}}}
$$

where $\varphi_{A}$ and $\varphi_{B}$ refer to the volume fractions of the components $\mathrm{A}$ and $\mathrm{B}$ respectively. $v_{\mathrm{A}}$ and $v_{\mathrm{B}}$ refer to the kinematic viscosities of the two pure components $\mathrm{A}$ and $\mathrm{B}$ respectively. Lobe suggested that if $\mathrm{A}$ is chosen as the component with lesser pure liquid viscosity and if the kinematically with composition, then the values of $\alpha^{*}{ }_{A} \alpha^{*}{ }_{B}$ are given by eq 6 and 7 , respectively. The values of the kinematic viscosities, $v_{\text {cal }}$ as estimated from eq 4 are given in Table 1.

$$
\begin{gathered}
\alpha_{\mathrm{A}}{ }^{=}-1.7 \ln \frac{v \mathrm{~B}}{v \mathrm{~A}} \\
\alpha_{\mathrm{B}}{ }^{=} 0.27 \ln \frac{v \mathrm{~B}}{v \mathrm{~A}}+\left(1.3 \ln \frac{v \mathrm{~B}}{v \mathrm{~A}}\right)^{1 / 2}
\end{gathered}
$$

The average percent deviations, $(\Delta \%)_{\mathrm{av},}$ and maximum percent deviation $(\Delta \%)_{\max }$ of the experimental values of $v$ from those obtained from eq 5 are recorded in Table 2. Tables 1 and 2 show that eq 3 estimates kinematic viscosities to a good degree of accuracy for mixtures of 1,2-dichloroethane with other compounds. Table 1 and 2 show that the values of $v$ estimated from equation 5 exhibit large percent deviations from the experimental values of $v$ in the case of the mixtures of 1,2dichloroethane with all above-mentioned compounds.

A simple additive relation [14] for predicting the mixture viscosity from the properties of pure components, when the pure components interactions are are taken as negligible, is the equation

$$
\ln v=x \ln v_{1}+(1-x) \ln v_{2}
$$

Where $v_{1}$ and $v_{2}$ refer to the dynamic viscosities of the two pure components 1 and 2 whose mole fractions are $x \&$ $1-x$ respectively, and $v$ is the dynamic viscosity of the mixture. In practice, however, deviations of the experimental values of the dynamic viscosities of the mixtures from those predicted by Eq. (8) are found to occur., thus indicating that explicit account of the contributions to the mixture viscosity due to interactions between components has to be taken.

The quantity $\Delta v$ have been calculated by taking values of $v$ for the different mixtures from the relation 


$$
\Delta v=v-x v_{1}-(1-x) v_{2}
$$

Where $v_{1}, v_{2}, v, x$ and $1-x$ have the same significance as in eq (2). The values of $\Delta v$ for the various system of $\mathrm{CH}_{2} \mathrm{ClCH}_{2} \mathrm{Cl}$ have been given in the Table 1, which shows that the values of $\Delta v$ are negative throughout the whole range of composition for $\mathrm{CH}_{2} \mathrm{ClCH}_{2} \mathrm{Cl}$-pyridine, $\mathrm{CH}_{2} \mathrm{ClCH}_{2} \mathrm{Cl}$ DMSO, and $\mathrm{CH}_{2} \mathrm{ClCH}_{2} \mathrm{Cl}$-tetrhydrofuran, whereas it is positive for the systems of $\mathrm{CH}_{2} \mathrm{ClCH}_{2} \mathrm{Cl}$-furan and $\mathrm{CH}_{2} \mathrm{ClCH}_{2} \mathrm{Cl}$-acetone. At $x 1=0.5$, the values of $\Delta v$ have the sequence

$(\Delta v)_{\text {pyridine }}>(\Delta v)_{\text {dimethylsulfoxide }}>(\Delta v)_{\text {tetrahydrofuran }}>$ $(\Delta v)_{\text {acetone }}>(\Delta v)_{\text {furan }}$

The values of $\Delta v$ can be discussed from the viewpoint of the existence of specific interaction leading to the formation of molecular complexes between the components of the different systems [4]. For systems where dispersion, induction and dipolar forces are operating, the values of $\Delta v$ are found to be negative, whereas the existence of specific interaction leading to the formation of adducts between the two components of various binary systems tends to make $\Delta v$ positive. The measurements of excess enthalpy $[1,2]$ have indicated that dibromomethane forms molecular complexes with the n-donor components. The large negative values of $\Delta v$ for dichloromethane-furan can be accredited to the high proportion of contributions to $\Delta v$ on account of the dispersion, dipolar and induction forces over those caused by specific interactions between the components. The ether oxygen in furan is a weak proton acceptor and can interact to form a hydrogen bond with a proton donor molecule. However, owing to the presence of double bonds in the ring, the oxygen becomes less basic, and therefore possibility of hydrogen bonding is much reduced, resulting large negative values of $\Delta v$. The effect of saturation of furan is marked and the values of $\Delta v$ for the $\mathrm{CH}_{2} \mathrm{ClCH}_{2} \mathrm{Cl}$-tetrahydrofuran system is positive, indicating strong specific interactions involving the heteroatoms. Dincer and Van Ness [15] determined the enthalpies of mixing of dichloromethane with THF and the maximum enthalpy changes were $-1343 \mathrm{~J} \mathrm{~mol}^{-1}$. This indicates that the interactions other than hydrogen bonding contribute significantly to the enthalpies of mixing. Thus $\mathrm{O}-\mathrm{Cl}$ interaction is also possible [2] as in the case of dibromomethane -THF system. The slightly negative values of $\Delta v$ dichloroethane-acetone system show that acetone forms molecular complexes with dichloroethane as in the case of acetylene tetrachloride with acetone[16], whereas this value is positive with dimethyl sulfoxide showing that dichloroethane forms strong adducts with DMSO. If we compare the structure of DMSO and acetone, they are similar. The only variation is that DMSO has $\mathrm{S}$ atom whereas acetone $\mathrm{O}$ atom. A vacant $3 \mathrm{~d}$ orbital is present in sulphur atom of DMSO in its electronic configuration, which facilitates the electron delocalization on the nearby carbon atom. Thus the three hydrogen atoms on the methyl groups of DMSO are, supposed to be more acidic than those of acetone [1]. The complex formation between DMSO and $\mathrm{CH}_{2} \mathrm{ClCH}_{2} \mathrm{Cl}$ are therefore believed to be stronger than those between $\mathrm{CH}_{2} \mathrm{ClCH}_{2} \mathrm{Cl}$ - acetone, which add to the positive values of $\Delta v$ in the DMSO- $\mathrm{CH}_{2} \mathrm{ClCH}_{2} \mathrm{Cl}$ system. The specific interaction is expected to be hydrogen bond formation between the hydrogen of 1,2-dichloroethane and proton acceptor groups. The positive values of $\Delta v$ for the system dichloroethane-pyridine undoubtedly indicates a strong hydrogen bond formation between lone pair electrons on $\mathrm{N}$ atom of pyridine and $\mathrm{H}$ atom of dichloroethane. The chance of the formation of charge transfer complexes via $\mathrm{Cl}-\pi$-electron interaction between dichloroethane and pyridine is believed to be present as recommended for the system of dibromomethane with pyridine in our earlier communication [2].

\section{Conclusions}

In conclusion, we note that the viscosity data show that binary liquid mixtures of $\mathrm{CH}_{2} \mathrm{CICH}_{2} \mathrm{CI}$ with pyridine, dimethyl -sulfoxide, acetone, furan and tetrahydrofuran show specific interaction between components. The complex formation between DMSO and $\mathrm{CH}_{2} \mathrm{ClCH}_{2} \mathrm{Cl}$ are believed to be stronger than those between $\mathrm{CH}_{2} \mathrm{ClCH}_{2} \mathrm{Cl}$ - acetone. The slightly negative values of $\Delta v$ dichloroethane-acetone system show that acetone forms molecular complexes with dichloroethane, whereas this value is positive with dimethyl sulfoxide showing that dichloroethane forms strong adducts with DMSO. The specific interaction is expected to be hydrogen bond formation between the hydrogen of 1,2dichloroethane and proton acceptor groups. The positive values of $\Delta v$ for the system dichloroethane-pyridine undoubtedly indicates a strong hydrogen bond formation between lone pair electrons on $\mathrm{N}$ atom of pyridine and $\mathrm{H}$ atom of dichloroethane. Also there is a possibility of formation of charge transfer complexes via $\mathrm{Cl}-\pi$-electron interaction between dichloroethane and pyridine is believed to be present. Viscosity data also shows that the large negative values of $\Delta v$ for dichloromethane-furan can be accredited to the high proportion of contributions to $\Delta v$ on account of the dispersion, dipolar and induction forces over those caused by specific interactions between the components. The ether oxygen in furan is a weak proton acceptor and forms hydrogen bond with $\mathrm{CH}_{2} \mathrm{ClCH}_{2} \mathrm{Cl}$. However, owing to the presence of double bonds in the ring, the oxygen becomes less basic, and therefore possibility of hydrogen bonding is much reduced, resulting large negative values of $\Delta v$. THF is saturated molecule and the values of $\Delta v$ for the $\mathrm{CH}_{2} \mathrm{ClCH}_{2} \mathrm{Cl}$-tetrahydrofuran system is positive, which indicates strong specific interactions. On the other hand, the complexation between $\mathrm{CH}_{2} \mathrm{ClCH}_{2} \mathrm{Cl}$ with acetone, DMSO,THF or pyridine can be attributed to the formation of strong hydrogen bonds between the hydrogen atom of $\mathrm{CH}_{2} \mathrm{ClCH}_{2} \mathrm{Cl}$ and the lone-pair electrons on the oxygen or nitrogen atom of acetone, DMSO, THF or pyridine.

\section{Acknowledgements}

Author is extremely grateful to Professor D. V. S. Jain, Department of Chemistry, Panjab University, Chandigarh(India) for encouragement during course of present investigation. 


\section{References}

[1] Tripathi, A. D. J. Chem. Eng. Data 2010, 55, 1421-1423.

[2] Tripathi, A. D. J. Chem. Eng. Data 2010, 55, 1113-1116.

[3] Tripathi, A. D.; Chadha, R. J. Chem. Eng. Data 1995, 40, 645646.

[4] Nath, J.; Dubey, S. N. J. Phys. chem.1981, 85, 886-889.

[5] Nath, J; Dixit, A. P. J. Chem. Eng. data 1984, 29, 317-319.

[6] Nath J.; Chaudhary,S. K. J. Chem. Eng. Data 1992, 37, 387-390.

[7] McAllister,R. A. AIChE J.1960,6, 427-431.

[8] Lobe, V. M. M. S. Thesis, University of Rochester, NY, (1973).

[9] Tuan, D. F. T.; Fuoss, R. M. J. Phys. Chem. 1960, 67, 13431347.
[10] Nath J.; Pandey, J. G. J. Chem. Eng. data, 1997,42(6),1133-1136.

[11] Riddick, J. A.; Bunger, W. B. Techniques of Chemistry, Vol. II. Organic Solvents; Physical Properties and Methods of Purification, $3^{\text {rd }}$ ed.; Wiley-Interscience: New York, 1970.

[12] Reid, R. C.; Prausnitz, J. M.; Sherwood, T. K. The Properties of Gases and liquids $3^{\text {rd }}$ ed.; McGraw-Hill; New York, 1977.

[13] Glass Tone, S; Laidle, K. J.; Eyring H.: The theory of rate processes (McGraw Hill, New York) 1941; Ch.9.

[14] Bloomfield, V. A.; Dewan, R. K. J. Phy. Chem. (USA) 1971, 75, 3113-19.

[15] Dincer, S.; Van Ness, J. Chem. Eng. Data 1971, 16 (3), 378379.

[16] Tripathi, A. D. J. App. Sol. Chemistry and Modeling, 2014, 3, 74-80. 